\title{
Role of CuO-ZnO Heterojunctions in Gas Sensing Response of CuO-ZnO Thick Films
}

\author{
Madhavrao K. Deore ${ }^{1}$, Vishwas B. Gaikwad ${ }^{2}$ and Gotan H. Jain ${ }^{3}$ \\ 1. Material Research Lab., Department of Physics, Arts, Science and Commerce College, Ozar (Mig)-422206, India \\ 2. Director, BCUD, Savitribai Phule Pune University, Pune 411007, India \\ 3. Department of Physics, SNJB's KKHA Arts, SMGL Commerce \& SPHJ Science College, Chandwad-423101, India
}

\begin{abstract}
The $\mathrm{CuO}$-doped $\mathrm{ZnO}$ thick films were prepared by the screen printing technique. The $\mathrm{CuO}$ doped $\mathrm{ZnO}$ composite materials were obtained by mixing AR grade (99.9\% pure) Zinc Oxide powder mechanochemically in acetone medium with various weight percentages of Copper Chloride $\left(\mathrm{CulCl}_{2} \cdot 2 \mathrm{H}_{2} \mathrm{O}\right)$ powder $(1,3,5,7$ and $9 \mathrm{wt} . \%)$. The prepared materials were sintered at 1,000 ${ }^{\circ} \mathrm{C}$ for $12 \mathrm{~h}$ in air ambience and ball milled to ensure sufficiently fine particle size. The films were characterized by different techniques with respect to their surface morphology and compositional property by means of SEM (scanning electron microscope) and EDXA (energy dispersive x-ray analysis). The surface morphology of the films was studied by SEM and it shows the films are porous in nature and petal-shaped grains of sizes varies from $220 \mathrm{~nm}$ to $250 \mathrm{~nm}$ were observed. The final composition of each film was determined by the EDXA analysis. The gas response of undoped $\mathrm{ZnO}$ and $\mathrm{CuO}$ doped $\mathrm{ZnO}$ films was studied for different gases such as $\mathrm{CO}, \mathrm{Cl}_{2}, \mathrm{NH}_{3}$, Ethanol, $\mathrm{H}_{2} \mathrm{~S}$ and $\mathrm{LPG}$ at operating temperature ranging from $50{ }^{\circ} \mathrm{C}$ to $400{ }^{\circ} \mathrm{C}$. The $7 \mathrm{wt}$. $\% \mathrm{CuO}$-doped $\mathrm{ZnO}$ film shows good response to $\mathrm{H}_{2} \mathrm{~S}$ gas $(100 \mathrm{ppm})$ at $250{ }^{\circ} \mathrm{C}$.
\end{abstract}

Key words: $\mathrm{CuO}-\mathrm{ZnO}$ heterojunctions, $\mathrm{H}_{2} \mathrm{~S}$, thick film, gas response, selectivity, response and recovery time.

\section{Nomenclature}

$O:$ Oxygen

Z: Zinc Cu- copper

At.\%: Atom percent

Wt.\%: Weight percent

$\mathrm{G}_{\text {air }}=$ Conductance of thick film in air

$\mathrm{G}_{\mathrm{gas}}=$ Conductance of thick film in gas

S: Gas response

\section{Greek letters}

$\mathrm{S}_{\text {area }}$ Specific surface area

$\rho$ - Density of functional material

\section{Introduction}

With the recent awareness of environmental pollution, there is a growing need for a reliable and inexpensive gas sensor. Thus, the use of sensors has been increasing at an astounding rate during the last

Corresponding author: Madhavrao K. Deore, Ph.D., associate professor, research fields: physics, metal oxide gas sensor, nano materiales. few decades for a variety of purposes such as detection and monitoring of hazardous gases, highly inflammable gases, humidity, etc. A wide range of gas sensors are developed using MOS (metal oxide semiconductors) because of their advantageous features like sensitivity to the air ambient conditions, low material cost, easy processing and simplicity in fabrication. The most commonly used $\mathrm{MOS} \mathrm{ZnO}$ [1, 2], $\mathrm{SnO}_{2}$ [3], $\mathrm{Fe}_{2} \mathrm{O}_{3}$ [4], $\mathrm{In}_{2} \mathrm{O}_{3}$ [5], $\mathrm{CeO}_{2}$ [6] in gas sensors are based on their change in electrical conductivity when they are exposed to test gases. At elevated temperatures $\left(100-600{ }^{\circ} \mathrm{C}\right)$, these materials show large variations of electrical conductivity in response to the presence of traces of reactive gases in air. Gas sensors based on MOS in a thick-film form, have been developed for detection and control of gases like $\mathrm{CO}, \mathrm{O}_{2}, \mathrm{NH}_{3}, \mathrm{NO}_{2}$, Ethanol, $\mathrm{H}_{2} \mathrm{~S}$, LPG, etc.

The gas sensing characteristics of the materials can be improved by incorporating some additives [7] into oxide films. Catalysts like $\mathrm{Pt}, \mathrm{Pd}, \mathrm{Ag}, \mathrm{Ru}$ and $\mathrm{Au}$ 
[8-11] are often added to the base material to improve gas sensitivity and selectivity which are expensive. However, low cost metals or metal oxides have also been doped to achieve higher sensitivity and selectivity [12].

The most general adsorption-desorption gas sensing mechanism [13, 14] of semiconductor gas sensors is a simple resistivity change, due to desorption of surface oxygen adsorbates via reactions with reducing gases such as $\mathrm{H}_{2} \mathrm{~S}, \mathrm{CO}$ and $\mathrm{H}_{2}$. The p-n hetero-contact concept is used in the present investigation, instead of adsorption-desorption mechanism, which was introduced in 1979 and has been applied as humidity sensors, liquid sensors and gas sensors. The hetero-contact concept was found very effective for the $\mathrm{H}_{2} \mathrm{~S}$ gas sensing at room temperature. The hetero-contact type works on the principle of a barrier mechanism, which needs no adsorption and desorption of oxygen for the detection of hazardous and highly inflammable gases. Some well-known materials for $\mathrm{H}_{2} \mathrm{~S}$ gas sensing are $\mathrm{SnO}_{2}-\mathrm{CuO}$ [15], $\mathrm{CuO}-\mathrm{ZnO}$ [16], $\mathrm{SnO}_{2}-\mathrm{ZnO}$ [17], CuO-BaTiO 3 [18], $\mathrm{SnO}_{2}-\mathrm{WO}_{3}$ [19].

In 1996, Sang-Jin-Jung et al. reported $\mathrm{CuO} / \mathrm{ZnO}$ hetero-contact type gas sensor is more sensitive to $\mathrm{CO}$ gas, In 2006, Mridha, S. et al. reported p-CuO/n- $\mathrm{ZnO}$ thin film heterojunction type gas sensor is more sensitive to $\mathrm{H}_{2}$ gas at 3,000 ppm level and in 2014, Ghosh, Amrita et al. development of a p-CuO/n- $\mathrm{ZnO}$ heterojunction and its application as a selective gas sensor including $\mathrm{CH}_{4}, \mathrm{H}_{2} \mathrm{~S}$ and $\mathrm{CO}$ in the presence of 10,000 ppm level. In the present work $\mathrm{CuO}$ has been doped in $\mathrm{ZnO}$ to enhance gas response and selectivity of $\mathrm{ZnO}$ sensor. $\mathrm{CuO}$ doping into $\mathrm{ZnO}$ shows reduction of the electrical conductivity of $\mathrm{ZnO}$ and the reduced conductivity of $\mathrm{ZnO}$ is proposed to be responsible for the increase of the gas sensitivity of $\mathrm{CuO}-\mathrm{ZnO}$ composite by increasing the current through $\mathrm{p}-\mathrm{n}$ junction.

\section{Experimental Setup}

\subsection{Preparation of Functional Materials}

The $\mathrm{CuO}$ doped $\mathrm{ZnO}$ composite materials were obtained by mixing AR grade (99.9\% pure) Zinc Oxide powder mechanochemically in acetone medium with various weight percentages of Copper Chloride $\left(\mathrm{CulCl}_{2} .2 \mathrm{H}_{2} \mathrm{O}\right)$ powder $(1,3,5,7$ and $9 \mathrm{wt} . \%)$. The prepared powders were sintered at $1,000{ }^{\circ} \mathrm{C}$ for $12 \mathrm{~h}$ in air ambience and ball milled to ensure a sufficiently fine particle size.

\subsection{Preparation of Thick Films}

The thixotropic paste was formulated by mixing the fine powder of functional material with ethyl cellulose (a temporary binder) with organic solvents such as butyl cellulose, butyl carbitol acetate and terpineol, etc. This paste was screen-printed [20, 21], on a glass substrate in a desired pattern $(1.5 \mathrm{~cm} \times 0.5 \mathrm{~cm})$. The films were dried under infrared radiation for 45 minutes to remove the organic vehicle and then fired at the peak temperature of $550{ }^{\circ} \mathrm{C}$ constantly for 30 min and is brought to room temperature in a muffle furnace.

\subsection{Thickness Measurements}

The thickness of the films was observed in the range from 65 to $75 \mu \mathrm{m}$. The reproducibility of thickness in the films was possible by maintaining proper rheology and thixotropy of the paste.

\section{Physical Characterization}

\subsection{Microstructural Analysis of the Films}

It is well known that gas sensing properties of metal oxide thick films are strongly dependent on its morphological features. A high surface area facilitates the chemisorption process by increasing the adsorption and desorption rates [20]. The surface morphology and chemical composition of the films were analyzed using a SEM [scanning electron microscope model JEOL 6300 (LA) Germany] coupled with an EDXA (energy dispersive x-ray analysis, JEOL, JED-2300, Germany). It shows the films are porous in nature and petal-shaped grains of sizes varies from $220 \mathrm{~nm}$ to $250 \mathrm{~nm}$ were observed. 
Fig. 1a shows the micrograph of undoped $\mathrm{ZnO}$ thick film. It consists of randomly distributed grains with smaller size and shape and with limited porosity. Figs. $1 \mathrm{~b}$ and $1 \mathrm{c}$ show that, at lower concentration of dopant, the numbers of $\mathrm{CuO}$ additives distributed on $\mathrm{ZnO}$ grains are very less as they are not sufficient to accelerate the sensing reaction with the target gas, hence it shows the poor sensitivity.

Figs. 1b-1d show that, at lower concentration of dopant, the numbers of $\mathrm{CuO}$ additives distributed on $\mathrm{ZnO}$ grains are very less. They are not sufficient to accelerate the sensing reaction with the target gas, hence it shows the poor sensitivity. Fig. 1e shows the micrograph of 7 wt.\% $\mathrm{CuO}$ doped $\mathrm{ZnO}$ thick film which was most sensitive. It showed that the grain size decreases giving large effective surface area. The larger surface area gives more response to react with the target gas. The film seems to be highly porous for oxygen adsorption. Also $\mathrm{CuO}$ segregates at the grain boundaries. The segregation of $\mathrm{CuO}$ around the boundary of $\mathrm{ZnO}$ forms a heterojunction between $\mathrm{ZnO}(\mathrm{n})$ and $\mathrm{CuO}(\mathrm{p})$, facilitating the efficient charge transfer, which enhances sensitivity and selectivity under certain conditions. Fig. If shows, large number of $\mathrm{CuO}$ additives are distributed uniformly over $\mathrm{ZnO}$. They are agglomerated around $\mathrm{ZnO}$ grains and the surface of the film becomes less porous. It resists reaching the target gas to the inter-grain boundary of $\mathrm{CuO}-\mathrm{ZnO}$. Also the agglomeration increases the particle size, hence effective surface to the volume ratio would decrease and less number of oxygen ions would be adsorbed on the film surface, hence it shows poor gas response.

\subsection{Elemental Analysis of the Films}

The elemental composition of undoped and $\mathrm{CuO}$ doped $\mathrm{ZnO}$ thick films with different concentrations were analyzed by energy dispersive spectrometer.

Table 1, shows the composition of the film doped at different level. At.\% of $\mathrm{Zn}, \mathrm{Cu}$ and $\mathrm{O}$ in each sample was observed to be non-stoichiometric. The $\mathrm{ZnO}$ film doped with 7 wt.\% $\mathrm{CuO}$ was observed to be most oxygen deficient. The deficiency or excess of the constituent material results in distorted band structure with corresponding increase in conductivity. The deficiency of the constituent material particles or an excess of it leads to the semi conducting behavior of the material [22].

The grain size of undoped and $\mathrm{CuO}$ doped $\mathrm{ZnO}$ thick films was determined from the SEM micrographs and the specific surface area was calculated by using Eq. (1)

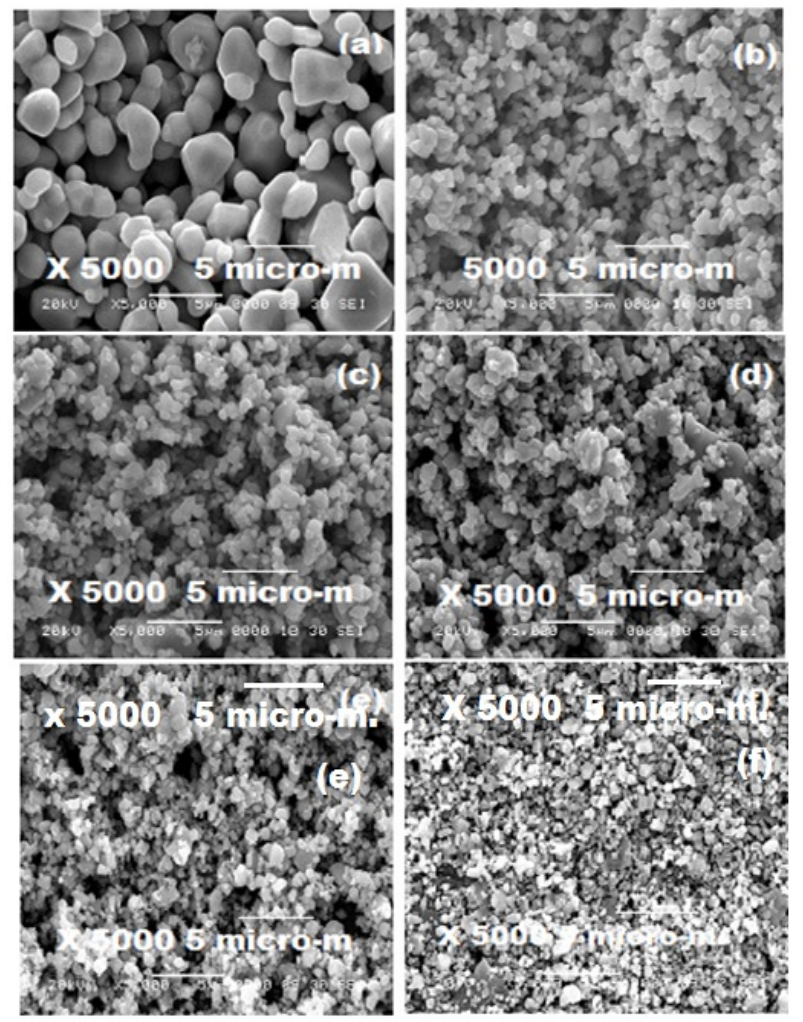

Fig. 1 SEM images of (a) undoped $\mathrm{ZnO}$, (b) 1 wt.\% (c) $3 w t . \%$ (d) 5 wt. \% (e) $7 w t . \%$ and (f) $9 w t . \%$ of $\mathrm{CuO}$ doped ZnO films.

Table 1 Quantative elemental analysis of undoped and $\mathrm{CuO}$ doped $\mathrm{ZnO}$ films.

\begin{tabular}{lllll}
\hline \multirow{2}{*}{ Doping level } & \multicolumn{4}{l}{ Elements (At.\%) } \\
\cline { 2 - 5 } & $\mathrm{O}$ & $\mathrm{Zn}$ & $\mathrm{Cu}$ & Total \\
\hline Undoped $\mathrm{ZnO}$ & 21.18 & 78.82 & - & 100 \\
1wt.\% CuO-ZnO & 41.46 & 58.27 & 0.27 & 100 \\
3wt.\% CuO-ZnO & 41.87 & 57.81 & 0.33 & 100 \\
5wt.\% CuO-ZnO & 39.91 & 59.92 & 0.17 & 100 \\
7wt.\% CuO-ZnO & 18.38 & 80.85 & 0.77 & 100 \\
9wt.\% CuO-ZnO & 43.90 & 55.72 & 0.38 & 100 \\
\hline
\end{tabular}




$$
S_{\text {area }}=\frac{6}{\rho \times D}
$$

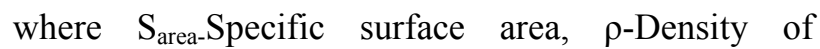
functional material, D-Grain size.

Table 2, shows the grain size and specific surface area of undoped and $\mathrm{CuO}$ doped $\mathrm{ZnO}$ thick films. It is evident that the increase in doping concentration reduces the grain size and increases the specific surface area.

The higher response may be attributed to the optimum porosity and largest effective surface area available to react with the gas. The response could be attributed to the adsorption-desorption type of sensing mechanism. The amount of oxygen adsorbed on the surface would depend on the number of $\mathrm{Cu}$ misfits to adsorb the oxygen which in turn would oxidize the exposed gas. When the optimum amount of $\mathrm{Cu}(0.77$ At.\%) is incorporated on the surface of the $\mathrm{ZnO}$ film, $\mathrm{Cu}$ species would be distributed uniformly throughout the surface of the film. As a result the initial resistance of the film is high and this amount would be sufficient to promote the catalytic reaction effectively and the overall change in the resistance on the exposure of $\mathrm{H}_{2} \mathrm{~S}$ leading to an increase in the gas response. When the amount of $\mathrm{Cu}$ on the surface of the film is less than the optimum, the surface dispersion may be poor and the sensitivity of the film was observed to be decreased, since the amount may not be sufficient to promote the reaction more effectively. On the other hand, as the amount of $\mathrm{Cu}$ on the surface is more than the optimum, the $\mathrm{Cu}$ atoms would be distributed more densely. Therefore the initial resistance of the film would decrease and the overall change in the resistance on the exposure of $\mathrm{H}_{2} \mathrm{~S}$ would be smaller leading to lower response.

\section{Sensing Performance}

The gas sensing performance of undoped $\mathrm{ZnO}$ and $\mathrm{CuO}$ doped $\mathrm{ZnO}$ thick films was studied using a "static gas sensing system" [23], shown in Fig. 2.

There were electrical feeds through the base plate.
The heater $(2,000$ watt) was fixed on the base plate to heat the sample under test up to required operating temperatures (from room temperature to $500{ }^{\circ} \mathrm{C}$ ). The current passing through the heating element was monitored using a relay operated with an electronic circuit with adjustable ON-OFF time intervals. A $\mathrm{Cr}$-Al thermocouple was used to sense the operating temperature of the sensor. The output of the thermocouple was connected to a digital temperature indicator. A gas inlet valve was fitted at one of the ports of the base plate. The required gas concentration inside the static system was achieved by injecting a known volume of a test gas using a gas-injecting syringe. The air was allowed to pass into the glass chamber after every gas exposure cycle.

The conductance of thick film was measured by means of conventional circuitry by applying constant voltage and measuring the current by digital Pico ammeter as a function of temperature in air as well as in $\mathrm{H}_{2} \mathrm{~S}, \mathrm{LPG}, \mathrm{CO}, \mathrm{NH}_{3}, \mathrm{Cl}_{2}$, and Ethanol vapour gas

Table 2 Grain size and specific surface area of undoped and $\mathrm{CuO}$ doped $\mathrm{ZnO}$ films.

\begin{tabular}{llll}
\hline Sample type & $\mathrm{Cu}($ At. \%) & $\begin{array}{l}\text { Grain size } \\
\mathrm{d}(\mathrm{nm})\end{array}$ & $\begin{array}{l}\text { Specific surface } \\
\text { area }\left(\mathrm{m}^{2} / \mathrm{gm}\right)\end{array}$ \\
\hline Undoped $\mathrm{ZnO}$ & - & 2207 & 0.48 \\
1wt.\% CuO-ZnO & 0.27 & 1333 & 8.69 \\
3wt.\% CuO-ZnO & 0.33 & 1349 & 9.90 \\
5wt.\% CuO-ZnO & 0.17 & 1278 & 11.84 \\
7wt.\% CuO-ZnO & 0.77 & 1156 & 14.61 \\
9wt.\% CuO-ZnO & 0.38 & 949 & 19.68 \\
\hline
\end{tabular}

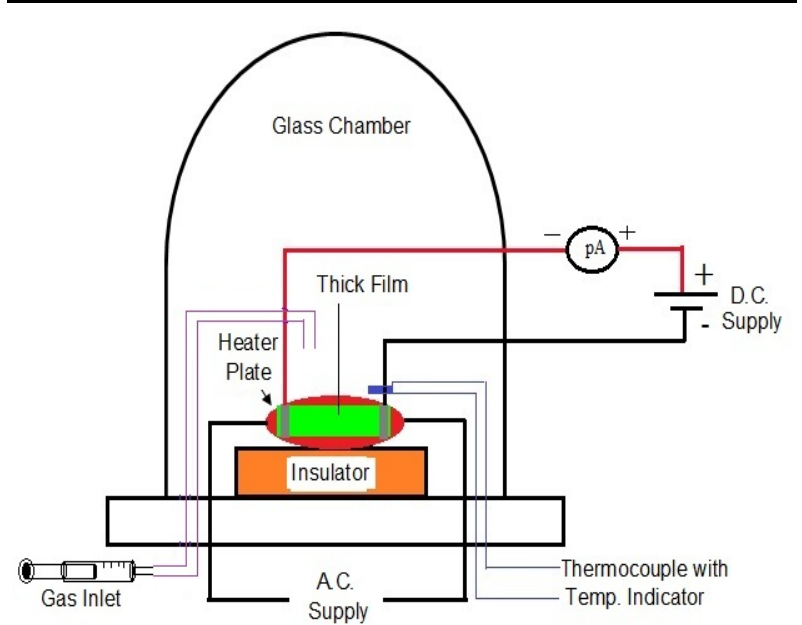

Fig. 2 The Schematic diagram of static gas sensing system. 
atmosphere. The operating temperature was varied at the interval of $50{ }^{\circ} \mathrm{C}$. From the measured conductance in air as well as in gas atmosphere, the gas response(S) was determined at particular operating temperature using the Eq. (2) [21].

$$
\mathrm{S}=\frac{\left(\mathrm{G}_{\text {gas }}-\mathrm{G}_{\text {air }}\right)}{\mathrm{G}_{\text {air }}}
$$

where $G_{\text {air }}=$ Conductance of thick film in air. $G_{\text {gas }}=$ Conductance of thick film in gas.

\subsection{Gas Sensing Performance of Undoped and $\mathrm{CuO}$ Doped ZnO Films}

Figs. $3 a$ and $3 b$ show the variation in the gas response of undoped and 7 wt.\% of $\mathrm{CuO}$ doped $\mathrm{ZnO}$ thick films. The films were tested for various gases viz: $\mathrm{CO}, \mathrm{Cl}_{2}, \mathrm{NH}_{3}, \mathrm{H}_{2} \mathrm{~S}, \mathrm{LPG}$ and Ethanol as the function of operating temperatures ranging from $50{ }^{\circ} \mathrm{C}$ to $400{ }^{\circ} \mathrm{C}$. It has been observed that the $7 \mathrm{wt} . \% \mathrm{CuO}$ doped $\mathrm{ZnO}$ thick film is more sensitive to $\mathrm{H}_{2} \mathrm{~S}$ $\operatorname{gas}(100 \mathrm{ppm})$ at temperature $250{ }^{\circ} \mathrm{C}$ while the undoped $\mathrm{ZnO}$ film shows very poor response to $\mathrm{H}_{2} \mathrm{~S}$ gas at temperature $300{ }^{\circ} \mathrm{C}$ than other tested gases viz: $\mathrm{CO}, \mathrm{Cl}_{2}, \mathrm{NH}_{3}$ and LPG. The gas response goes on increasing with increase in operating temperature, attains its maximum (at $250{ }^{\circ} \mathrm{C}$ ) and then decreases with a further increase in operating temperature. It is clear from the figure that the optimum operating temperature for $\mathrm{H}_{2} \mathrm{~S}$ gas is $250{ }^{\circ} \mathrm{C}$. The undoped $\mathrm{ZnO}$ is notable less sensitivity than the doped $\mathrm{ZnO}$. Thus the dopants or an additive increases sensitive of gas sensor by enhancing the chemisorptions of the specific gases [24].

Fig. 4 shows the variation in $\mathrm{H}_{2} \mathrm{~S}$ gas response with operating temperature of undoped and $\mathrm{CuO}$ doped $\mathrm{ZnO}$ films at different doping concentrations (1, 3, 5, 7 and 9 wt.\%) as a function of operating temperatures ranging from $50{ }^{\circ} \mathrm{C}$ to $400{ }^{\circ} \mathrm{C}$. It is evident that the gas response increases with increase in concentration of dopant $(\mathrm{CuO})$ up to optimum level and further decreases with increase in dopant concentration.
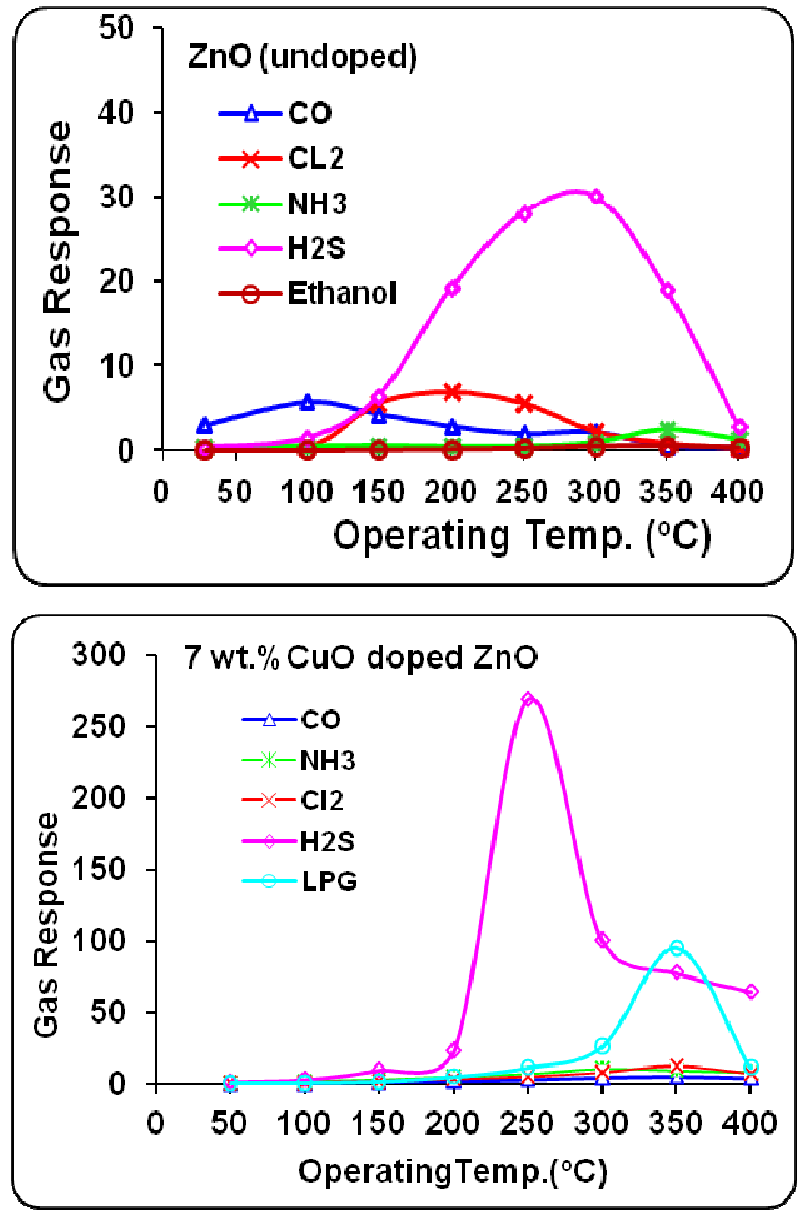

Fig. 3 Variation in gas response with operating temperature of (a) undoped and (b) $7 \mathrm{wt} \% \% \mathrm{CuO}$ doped ZnO thick films.

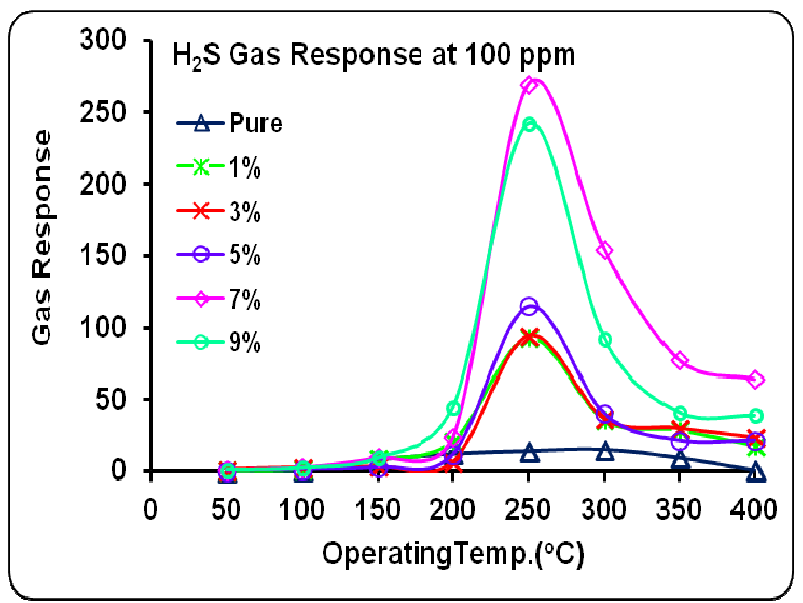

Fig. 4 Variation in $\mathrm{H}_{2} \mathrm{~S}$ gas response with operating temperature of undoped and $\mathrm{CuO}$ doped $\mathrm{ZnO}$ film.

\subsection{Effect of Gas Concentrations on CuO Doped $\mathrm{ZnO}$} Film

Fig. 5 shows the variation of $\mathrm{H}_{2} \mathrm{~S}$ gas response with 
different gas concentrations at optimum temperature $250{ }^{\circ} \mathrm{C}$. Gas response was observed to have increased continuously by increasing the gas concentration from $50 \mathrm{ppm}$ to $1,000 \mathrm{ppm}$. If the gas concentration increases above 1,000 ppm, the monolayer of the gas molecules formed on the surface could cover the whole surface of the film. The excess gas molecules would remain idle and would not reach the surface active sites of the film. So, the response at higher concentrations of the gas was not expected to increase in large extent. Thus, the active region of the film is up to $1,000 \mathrm{ppm}$.

\subsection{Selectivity of 7 wt.\% CuO Doped ZnO Film}

The selectivity is the ability of a sensor to respond of certain gas in the presence of other gases. Percentage selectivity of one gas over the other is defined as the ratio of maximum response of other gas to the maximum response of the target gas at the optimum temperature. It was calculated by Eq. (3) [25].

$$
\% \text { Selectivity }=\frac{\mathrm{s}_{(\text {other gas })}}{\mathrm{S}_{(\text {target gas })}}
$$

where $\mathrm{S}_{(\text {other gas) }}=$ maximum response to other gas,

$\mathrm{S}_{(\text {target gas })}=$ maximum response to target gas.

The bar diagram in Fig. 6 indicating percentage selectivity of thick $\mathrm{ZnO}$ film doped with 7 wt.\% $\mathrm{CuO}$ and operated at different operating temperatures for different test gases. It was clear from the bar diagram that the doped thick film is more selective to $\mathrm{H}_{2} \mathrm{~S}$ gas against the other gases viz $\mathrm{CO}, \mathrm{Cl}_{2}$, and $\mathrm{NH}_{3}$. Thus, the dopants or additives increases selective of gas sensor by enhancing the chemisorptions of the specific gases.

\subsection{Response and Recovery Time of 7 wt.\% $\mathrm{CuO}$ Doped ZnO Film}

The response/recovery time is an important parameter used for characterizing gas sensor sensors. The time taken for the sensor to attain $90 \%$ of maximum change in resistance on exposure to gas is the response time and the time taken by the sensor to get back $90 \%$ of the original resistance is the recovery time [26].

Fig.7 shows the variations in $\mathrm{H}_{2} \mathrm{~S}$ (100 ppm) response of with time at temperature $250{ }^{\circ} \mathrm{C}$ for 7

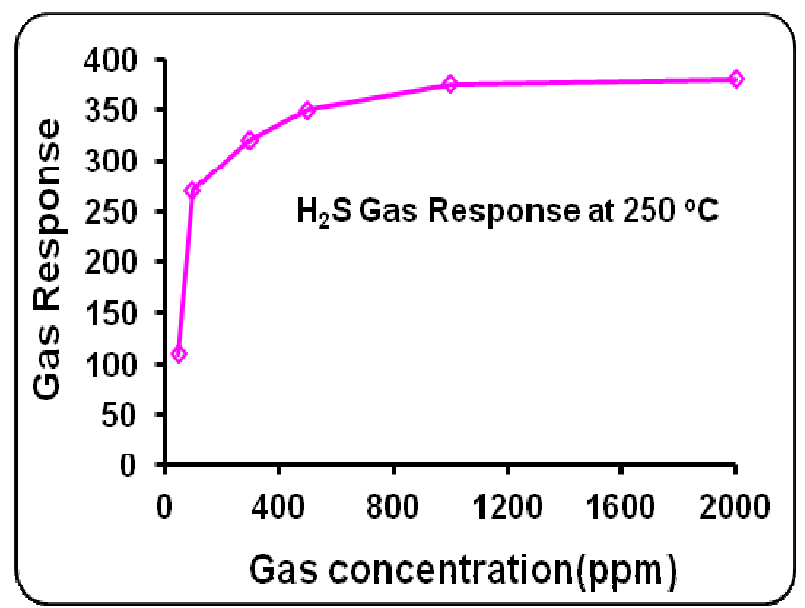

Fig. 5 Variation in $\mathrm{H}_{2} \mathrm{~S}$ gas response with gas concentration of $7 \mathrm{wt}$ \% $\mathrm{CuO}$ doped $\mathrm{ZnO}$ film.

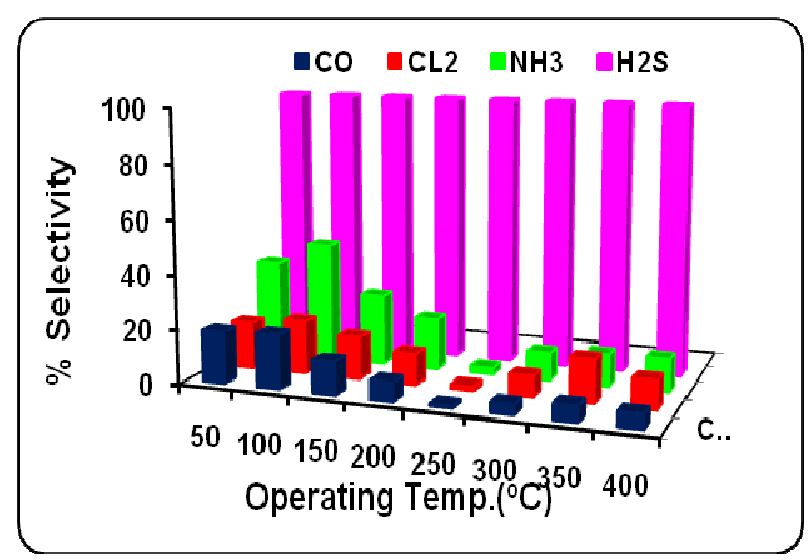

Fig. 6 \% Selectivity of 7 wt. \% CuO- doped $\mathrm{ZnO}$ film to $\mathrm{H}_{2} \mathrm{~S}$ gas against other gases.

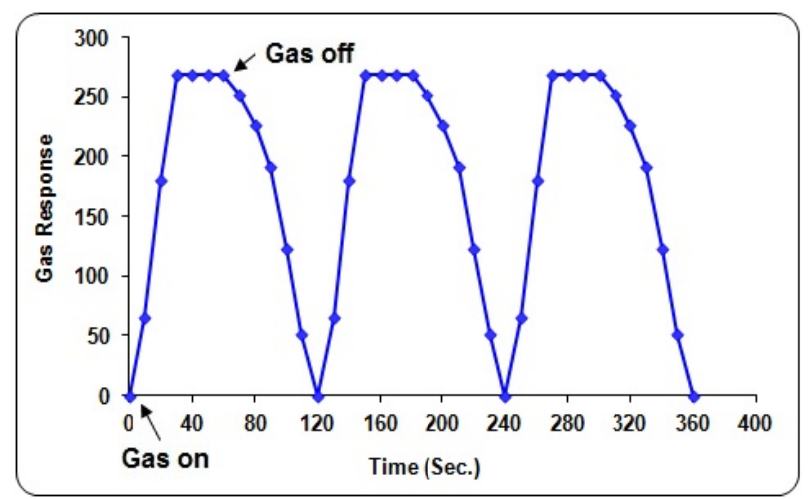

Fig. 7 Response transients of the 7 wt.\% $\mathrm{CuO}$ doped $\mathrm{ZnO}$ thick film to $\mathrm{H}_{2} \mathrm{~S}$ (100 ppm). 
wt. \% $\mathrm{CuO}$ doped $\mathrm{ZnO}$ film. The response was quick $(\sim 30$ s) while the recovery time was fast $(\sim 120$ s $)$. The quick response may be due to faster oxidation of gas. The long recovery time would be due to the conversion of $\mathrm{p}-\mathrm{CuS} / \mathrm{n}-\mathrm{ZnO}$ to again its initial chemical status $(\mathrm{p}-\mathrm{CuO} / \mathrm{n}-\mathrm{ZnO})$, it was essential to heat it above $200{ }^{\circ} \mathrm{C}$ in air atmosphere after every $\mathrm{H}_{2} \mathrm{~S}$ sensing cycle.

\section{Discussion}

\section{$5.1 \mathrm{H}_{2} \mathrm{~S}$-Sensing Mechanism of Surface Cupricated ZnO Thick Film Resistor}

The gas sensing mechanism of the metal oxide semiconductor sensors belongs to the surface controlled type, which is based on the change in conductance of the semiconductor. The oxygen adsorbed on the surface directly influence to the conductance of metal oxide based sensors. Oxygen adsorbed on the oxide crystals surface as ions are formed by abstracting free electrons from the metal oxide semiconductors, reducing the electrical conductivity. The amount of oxygen adsorbed on the sensor surface depends on the operating temperature, concentration of additives, particle size, and specific surface area of the sensor. In the aerial atmosphere where the partial pressure of oxygen is taken as constant, oxygen is adsorbed on sensor surfaces in the form of $\mathrm{O}^{-}, \mathrm{O}_{2}^{-}$and $\mathrm{O}^{2-}$, depending on the temperature. The state of oxygen on the surface of metal oxide sensor undergoing the following reactions [27-30]

$$
\begin{aligned}
& \mathrm{O}_{2(\text { gas })} \rightarrow \mathrm{O}_{2(\text { ads })} \\
& \mathrm{O}_{2(\text { ads })}+\mathrm{e}^{-} \stackrel{\text { up to } 200 \mathrm{o}_{\mathrm{C}}}{\longrightarrow} \mathrm{O}_{2(\text { ads })}^{-} \\
& \mathrm{O}_{2(\text { ads })}^{-}+\mathrm{e}^{-\stackrel{\text { up to } 400 \mathrm{o}_{\mathrm{C}}}{\longrightarrow}} 20_{(\text {ads })}^{-} \\
& \mathrm{O}_{(\text {ads })}^{-}+\mathrm{e}^{-\stackrel{\text { above } 400 \mathrm{o}_{\mathrm{C}}}{\longrightarrow}} \mathrm{O}_{(\text {ads })}^{2-}
\end{aligned}
$$

These oxygen adsorbates $\left(\mathrm{O}_{2}^{-}, \mathrm{O}^{-}\right.$and $\left.\mathrm{O}^{2-}\right)$ on the surface of metal oxide semiconductor can induce an electron-depleted surface region, resulting in the increase of surface potential barrier and electrical resistance.

The $\mathrm{CuO}$ which is oxygen excess shows the p-type conductivity by holes and oxygen deficient $\mathrm{ZnO}$ shows the n-type conductivity by electrons. In an oxidizing atmosphere, a thick charged depletion layer is formed across the grain boundaries of $\mathrm{ZnO}$ and $\mathrm{CuO}$ which would be formed as $\mathrm{p}-\mathrm{n}$ heterojunctions shown in Fig. 8a. The electron associated with this charged species was drawn from the conduction band of bulk material, leading to an increasing resistance of the film. As a result, a potential barrier appears at boundary forming a continuous chain of $p-n-p-n$ junctions. The band diagram of hetrojunction between p-type $(\mathrm{CuO})$ and n-type $(\mathrm{ZnO})$ semiconductor at equilibrium is as shown in Fig. 8b. The discontinuity in the conduction band allows the electrons to spill over

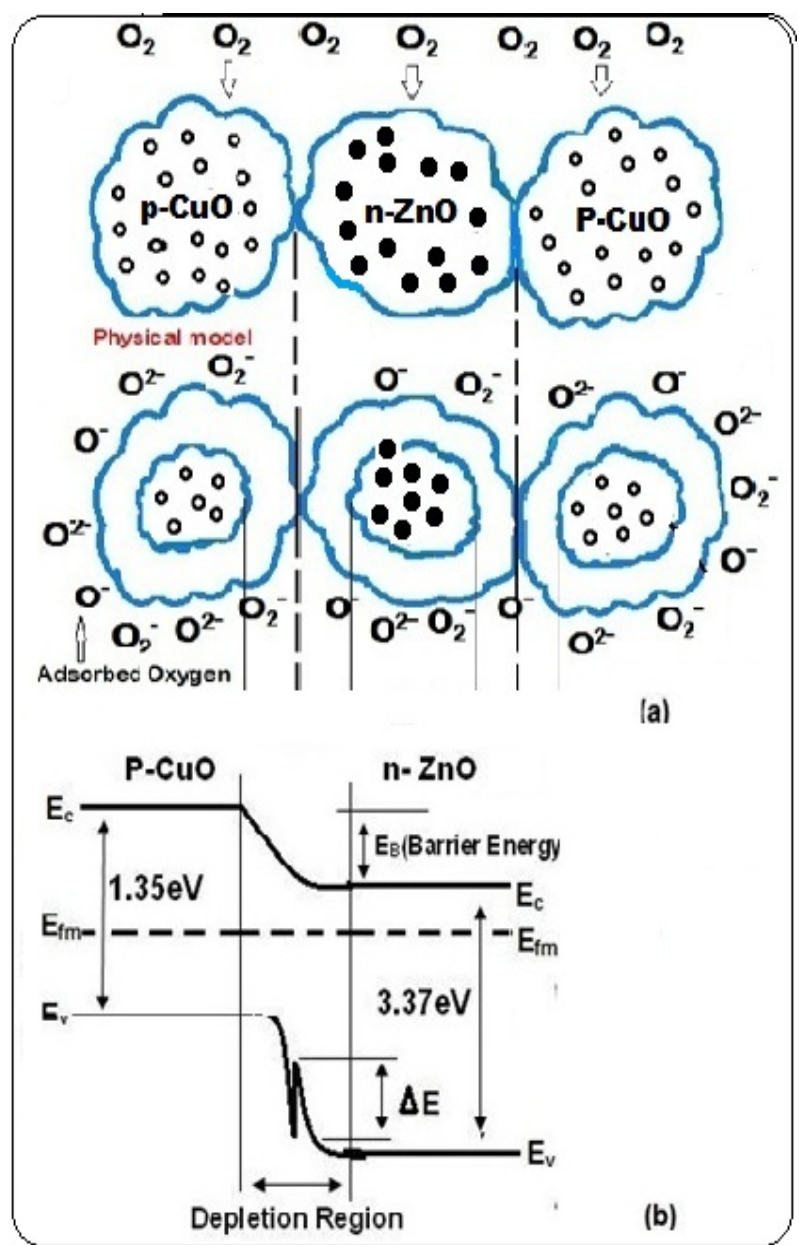

Fig. 8 Schematic diagram of $\mathrm{CuO}-\mathrm{ZnO}$ sensing mechanism (a) p-n-p-n-hetro Junction, (b) Energy band diagram of heterojunctions at equilibrium. 
from the donor $\mathrm{CuO}$ to $\mathrm{ZnO}$, where they became trapped in the potential well [31].

When film exposed to reducing $\mathrm{H}_{2} \mathrm{~S}$ gas, the gas molecules get oxidized with the adsorbed oxygen ions $\left(\mathrm{O}^{-}, \mathrm{O}_{2}^{-}\right.$and $\left.\mathrm{O}^{2-}\right)$ and there is desorption of oxygen. The reaction of $\mathrm{H}_{2} \mathrm{~S}$ gas with the adsorbed oxygen ions at the specific temperature $250{ }^{\circ} \mathrm{C}$ where the film shows the maximum gas response can be represented as:

$$
\mathrm{H}_{2} \mathrm{~S}+3 \mathrm{O}^{-} \stackrel{250 \mathrm{o}_{\mathrm{C}}}{\longrightarrow} \mathrm{H}_{2} \mathrm{O}+\mathrm{SO}_{2} \uparrow+3 \mathrm{e}^{-}
$$

Simultaneously the $\mathrm{CuO}$ on the film react with the $\mathrm{H} 2 \mathrm{~S}$ gas and converted into $\mathrm{CuS}$, the reaction can be represented as:

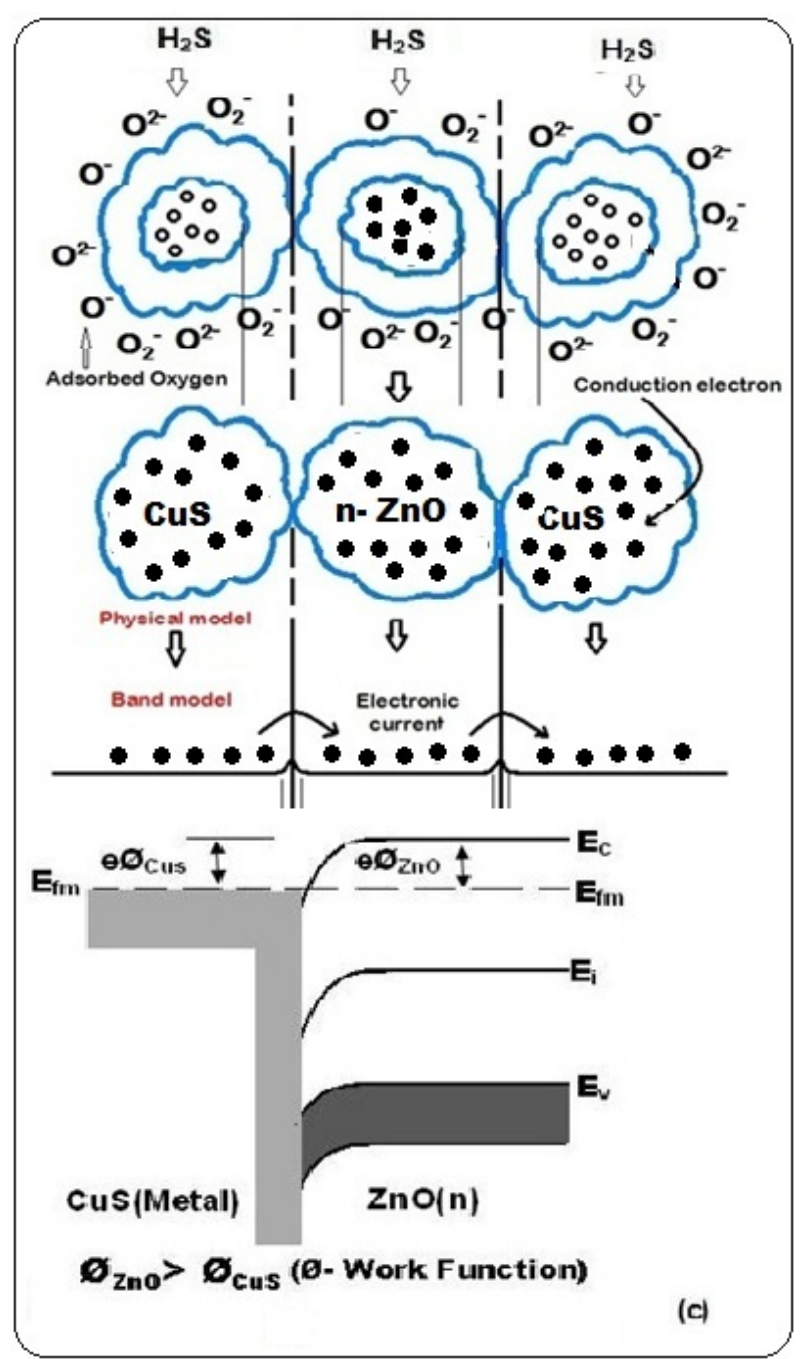

Fig. 9 Schematic energy band diagram of metal CuS $-\mathrm{ZnO}(\mathrm{n})$ at equilibrium.

$$
\mathrm{CuO}+\mathrm{H}_{2} \mathrm{~S} \stackrel{250 \mathrm{O}_{\mathrm{C}}}{\longrightarrow} \mathrm{CuS}+\mathrm{H}_{2} \mathrm{O}
$$

The CuS is known as metallic in nature and thus p-n-p-n hetrostructure as well as charge depletion layer would be destroyed and transformed to metal (CuS)-semiconductor (n-type $\mathrm{ZnO}$ ) configuration. A typical band diagram at equilibrium is as shown in Fig. 9. The work function of $\mathrm{CuS}$ is lower than $\mathrm{ZnO}$ (n-type), In this situation the Fermi levels are aligned at equilibrium by transferring electron from lower work function $\mathrm{CuS}$ to higher work function $\mathrm{ZnO}$, Since there is no barrier between them which results in decrease of electrical resistance and gives the higher response to $\mathrm{H}_{2} \mathrm{~S}$ gas.

The increase in resistance back to the original value once the $\mathrm{H}_{2} \mathrm{~S}$ atmosphere ceases to exist. It is because of the $\mathrm{CuS}$ convert back to the $\mathrm{CuO}$, when heated in an air at the operating temperature of about $200{ }^{\circ} \mathrm{C}$ and returns to normal its state and the change is given by following reaction $[28,32,33]$ :

$$
2 \mathrm{CuS}+4 \mathrm{O}_{2} \stackrel{200 \mathrm{o}_{\mathrm{C}}}{\longrightarrow} 2 \mathrm{CuO}+2 \mathrm{SO}_{2} \uparrow
$$

and the potential barrier appears again.

\section{Conclusions}

(1) The undoped $\mathrm{ZnO}$ film shows the poor response to the various test gases viz: $\mathrm{CO}, \mathrm{Cl}_{2}, \mathrm{NH}_{3}, \mathrm{H}_{2} \mathrm{~S}$ and Ethanol;

(2) The undoped $\mathrm{ZnO}$ thick films were doped by adding the Copper Chloride $\left(\mathrm{CulCl}_{2} \cdot 2 \mathrm{H}_{2} \mathrm{O}\right)$ additives by mechanochemicaly at different wt.\%;

(3) The doped $\mathrm{ZnO}$ films would form the $\mathrm{p}(\mathrm{CuO})-\mathrm{n}$ $(\mathrm{ZnO})$ heterojunctions which attributes the high film resistance;

(4) The barrier height of $\mathrm{p}-\mathrm{CuO} / \mathrm{n}-\mathrm{ZnO}$ heterojunctions decreased markedly due the chemical transformation of highly resistive $\mathrm{p}-\mathrm{CuO}$ into well conducting $\mathrm{CuS}$ leading to drastic decrease in resistance;

(5) The 7 wt.\% $\mathrm{CuO}$ doped $\mathrm{ZnO}$ film shows the good response to $\mathrm{H}_{2} \mathrm{~S}(100 \mathrm{ppm})$ at $250{ }^{\circ} \mathrm{C}$; 
(6) The $\mathrm{CuO}$-doped $\mathrm{ZnO}$ films showed the rapid response $(\sim 30 \mathrm{~s})$ and recovery time $(\sim 120 \mathrm{~s})$ to $\mathrm{H}_{2} \mathrm{~S}$;

(7) The film doped with $\mathrm{CuO}$ is more selective to $\mathrm{H}_{2} \mathrm{~S}$ gas against the other test gases.

\section{Acknowledgments}

The author is thankful to Smt. Nilimatai Pawar, Sarchitnis, M. V. P. Samaj, Nashik, India, Dr. A. P. Patil, Principal, Arts, Science and Commerce College, Ozar (Mig), India, for encouraging me for my research work.

\section{References}

[1] Trivikrama, Rao, G. S., and Tarakarama, Rao, D. 1999. "Gas Sensitivity of $\mathrm{ZnO}$ Based Thick Film Sensor to $\mathrm{NH}_{3}$ at Room Temperature." Sens. Actuators B 55: 166-9.

[2] Roy, S., and Basu, S. 2002. "Improved Zinc Oxide Film for Gas Sensor Applications.” Bull. Mater. Sci. 25: 513-5.

[3] Yu, J. H., and Choi, G. M. 1998. "Electrical and CO Gas Sensing Properties of $\mathrm{ZnO}-\mathrm{SnO}_{2}$ Composites." Sens. Actuatators B 52: 251-6.

[4] Lee, E. T., Jang, G. E., Kim, C. K., and Yoon, D. H. 2001. "Fabrication and Gas Sensing Properties of $\mathrm{Fe}_{2} \mathrm{O}_{3}$ Thin Film Prepared by Plasma Enhanced Chemical Vapor Deposition (PECVD)." Sens. Actuators B: Chem. 77: 221-7.

[5] Kim, S. R., Hong, H. K., Kwon, C. H. Yun, Lee, D. H. K., and Sung, Y. K. 2000. "Ozone Sensing Properties of $\mathrm{In}_{2} \mathrm{O}_{3}$-Based Semiconductor Thick Films." Sens. Actuators B: Chem. 66: 59-62.

[6] Bene, R., Perczel, I. V., Reti, F., F. Meyer, A., Fleisher, H., and Meixner, H. 2000. "Chemical Reactions in the Detection of Acetone and $\mathrm{NO}$ by a $\mathrm{CeO}_{2}$ Thin Film." Sens. Actuators B: Chem.71: 36-41.

[7] Yamazoe, N., Kurakowa, Y., and Seiyama, T. 1983. "Effects of Additives on Semiconductor Gas Sensors." Senors and Actuators B 4: 283-9.

[8] Senguttuvan, T. D., Rai, R., and Lakshmikumar, S. T. 2007. "Gas Sensing Properties of Lead Doped Tin Oxide Thick Films.” Material Letters 61: 582-4.

[9] Gaikwad, V. B., Deore, M. K., Khanna, P. K., Kajale, D. D., Shinde, S. D., Chavan, D. N., and Jain, G. H. 2009. "Studies on Gas Sensing Performance of Pure and Nano-Ag Doped ZnO Thick Film Resistors." Recent Adv. in Sensing Technology 49: 293-307.

[10] Wang, Y. D., Wu, X. H., Su, Q., Lee, Y. F., and Zhou, Z. L. 2001. "Ammonia Sensing Characteristics of Pt and $\mathrm{SiO}_{2}$ Doped $\mathrm{SnO}_{2}$ Materials." Solid-State Electron 45: 347-50.
[11] Chiorino, F. A., Tsubota, S., and Haruta, M. 1995. "An IR Study of CO-sensing Mechanism on Au/ZnO." Sens. Actuators B: Chem. 25: 540-3.

[12] Moseley, P. T., and Crocker, A. J. 1996. Sensor Materials. Bristol: Institute of Physics Publishing.

[13] Moseley, P. T., Norris, J. O. W., Williams, D. E., and Hilger, A. 1991. Techniques and Mechanisms in Gas Sensing. FL: CRC Press. Chap.4, 108.

[14] Noboru, Y. 2005. "Toward Innovations of Gas Sensor Technology." Sensors and Actuators B 108: 2-14.

[15] Liu, J. H., Huang, X. J., Ye, G., Liu, W., Jiao, W. L., Zhou, Z. B., and $\mathrm{Yu}$, Z. L. 2003. " $\mathrm{H}_{2} \mathrm{~S}$ Detection Sensing Characteristic of $\mathrm{CuO} / \mathrm{SnO} 2$ Sensor." Sensors 3: 110-8.

[16] Aygün, S., and Cann, D. 2005. "Hydrogen Sensitivity of Doped $\mathrm{CuO} / \mathrm{ZnO}$ Heterocontact." Sensors. Sens. Actuat. B. 106: 837-42.

[17] Mondal, B., Basumatari, B., Das, J., Roychaudhury, C., Saha, H., and Mukherjee, N. 2014. " $\mathrm{ZnO}-\mathrm{SnO}_{2}$ Based Composite Type Gas Sensor for Selective Hydrogen Sensing." Sensors and Actuators B: Chemical 194: 389-96.

[18] Liao, B., Wei, Q., Wang, K. Y., and Liu, Y. X. 2001. "Study on $\mathrm{CuO}-\mathrm{BaTiO}_{3}$ Semiconductor $\mathrm{CO}_{2}$ Sensor." Sensors and Actuators B: Chemical 80: 208-14.

[19] Ling, Z., and Leach, C. 2004. "The Effect of Relative Humidity on the $\mathrm{NO}_{2}$ Sensitivity of a $\mathrm{SnO}_{2} / \mathrm{WO}_{3}$ Heterojunction Gas Sensor." Sens. Actuat. B 102: 102-6.

[20] Patil, D. R., Patil, L. A., and Amalnerkar, D. P. 2007. "Ethanol Gas Sensing Properties of $\mathrm{Al}_{2} \mathrm{O}_{3}$ Doped $\mathrm{ZnO}$ Thick Film Resistors.” Bull. Mater. Sci. 30 (6): 553-9.

[21] Jain, G. H., and Patil, L. A. 2007. "CuO-doped BST Thick Film for ppb Level $\mathrm{H}_{2} \mathrm{~S}$ Gas Sensing at Room Temperature." Sensors and Actuators B 123: 246-53.

[22] Sedky, A., Al-Sawalha, A., and Yassin, A. M. 2008. "Enhancement of Electrical Conductivity of $\mathrm{ZnO}$ Ceramic Varistor by Al Doping." Egypt. J. Solids 31: 205-15.

[23] Deore, M. K. 2013. "Physical, Electrical Properties and Gas Sensing Performance of Pure and NiO-Modified ZnO Thick Films." Sensor Letters 11 (10): 1919-24.

[24] Jain, G. H., and Patil, L. A. 2006. "Gas Sensing Properties of $\mathrm{Cu}$ and $\mathrm{Cr}$ Activated BST Thick Films." Bulletin of Material Science 29 (4): 403-11.

[25] Jain, G. H., Patil, L. A., and Gaikwad, V. B. 2007. "Studies on Gas Sensing Performance of (Ba0.8Sr0.2) (Sn0.8Ti0.2) O3 Thick Film Resistors." Sensors and Actuators B: Chemical 122: 605-12.

[26] Deore, M. K., and Jain, G. H. 2014. "Studies on Ethanol Gas Sensing Properties of $\mathrm{Al}_{2} \mathrm{O}_{3}$-doped $\mathrm{ZnO}$ Thick Films." Journal of Petroleum Science Research (JPSR) 3 (2): 60-7.

[27] Besenbacher, F., and Nørskov, J. K. 1993. "Oxygen 
Chemisorption on Metal Surfaces: General Trends for $\mathrm{Cu}$, Ni and Ag." Progress in Surface Science 44: 5-66.

[28] Morrison, S. R. 1987. "Selectivity in Semiconductor Gas sensors." Sens. Actuators B 12: 425-40.

[29] Arshak, K., and Gaidan, I. 2005. "Gas Sensing Properties of $\mathrm{ZnFe}_{2} \mathrm{O}_{4} / \mathrm{ZnO}$ Screen-Printed Thick Films." Sensors and Actuators B 111-2: 58-62.

[30] Ghimbeu, C. M., Schoonman, J., Lumbreras, M., and Siadat, M. 2007. "Electrostatic Spray Deposited Zinc Oxide Films for Gas Sensor Applications." Applied Surface Science 253: 7483.
[31] Jinhaui, L., Xingjiu, H., Gang, Y., Wei, L., Zhen, J., Wanglian, C., Zhongbai, Z., and Zenglian, Y. 2003. " $\mathrm{H}_{2} \mathrm{~S}$ Detection Sensing Characteristics of $\mathrm{CuO} / \mathrm{SnO}_{2}$ Sensor." Sensor (3): 110-8.

[32] Korotcenkov, G. 2007. "Metal Oxide for Solid State Gas Sensor: What Determines Our Choice?" Material Science and Engineering B 1399: 1-23.

[33] Wagh, M. S., Patil, L. A., Tanay, S., and Amalnerkar, D. P. 2004. "Surface Cupricated $\mathrm{SnO}_{2}-\mathrm{ZnO}$ Thick Films as a $\mathrm{H}_{2} \mathrm{~S}$ Gas Sensor." Materials Chemistry and Physics 84: 228-33. 